\title{
Consumption patterns of sweetened food and drink products in a Catholic Middle Eastern Canadian community
}

\author{
Jean-Claude Moubarac ${ }^{1,2, *}$, Olivier Receveur ${ }^{3}$, Margaret Cargo ${ }^{4}$ and Mark Daniel ${ }^{4}$ \\ ${ }^{1}$ Núcleo de Pesquisas Epidemiológicas em Nutricão e Saúde, Universidade de São Paulo, Av. Dr. Arnaldo 715, \\ 01255-000, São Paulo, SP, Brasil: 'École de Santé Publique, Université de Montréal, Montréal, Québec, \\ Canada: ${ }^{3}$ Département de Nutrition, Université de Montréal, Montréal, Québec, Canada: ${ }^{4}$ School of Health \\ Sciences, University of South Australia, Adelaide, South Australia, Australia
}

Submitted 2 August 2012: Final revision received 22 0ctober 2012: Accepted 23 November 2012: First published online 3 January 2013

\begin{abstract}
Objective: The present study describes the consumption patterns of sweetened food and drink products in a Catholic Middle Eastern Canadian community and examines its associations with physical activity, sedentary behaviours and BMI. Design: A two-stage cross-sectional design was used. In Stage 1 ( $n$ 42), $24 \mathrm{~h}$ recalls enabled the identification of sweetened products. In Stage 2 ( $n$ 192), an FFQ was administered to measure the daily consumption of these products and to collect sociodemographic and behavioural data. Sweetened products were defined as processed culinary ingredients and ultra-processed products for which total sugar content exceeded $20 \%$ of total energy.

Setting: Three Catholic Middle Eastern churches located in Montreal, Canada.

Subjects: Normoglycaemic men and women (18-60 years old).

Results: Twenty-six sweetened products represented an average consumption of $75 \cdot 4 \mathrm{~g}$ total sugars/d or $15 \cdot 1 \%$ of daily energy intake ( $n 190,56 \%$ women). Soft drinks, juices, sweetened coffee, chocolate, cookies, cakes and muffins were the main sources of consumption and mostly consumed between meals. Age (exp $(\beta)=0.99 ; P<0 \cdot 01)$, physical activity $(\exp (\beta)=1 \cdot 08 ; P<0 \cdot 01)$ and recreational computer use $(\exp (\beta)=1.17 ; P<0 \cdot 01)$ were independently associated with sweetened product consumption. The association between sweetened product consumption and physical activity was U-shaped. BMI was not significantly associated with sweetened product consumption but all participants regardless of BMI were above the WHO recommendation for free sugars.

Conclusions: Being physically active and spending less time using a computer may favour a reduced consumption of sweetened products. Very active individuals may, however, overconsume such products.
\end{abstract}

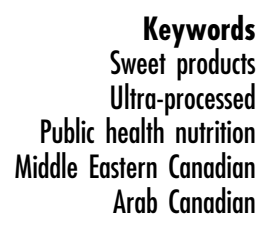

Keywords Sweet products tra-processed Arab Canadian
The prevalences of overweight and obesity, as well as their associated risk factors, differ greatly across ethnic groups in Canada ${ }^{(1)}$. Canadians of Middle East (or Arab) origin represent $>1 \cdot 2 \%$ of the total Canadian population and comprise one of the largest non-European ethnic groups in the country ${ }^{(2)}$. After adjusting for socio-economic factors, Middle Eastern Canadians are found more likely to be obese than individuals from the white, Chinese, Japanese and South Asian communities ${ }^{(3)}$. Additionally, long-term Middle Eastern migrants in Canada ( $\geq 11$ years) are found to be more overweight and obese than more recent immigrants (0-10 years) ${ }^{(1)}$. The high prevalence of excessive weight among Arab Canadians and the finding that the prevalence increases with time may result from the adoption of dietary and behavioural risk factors uncommon to the environment of their home countries prior to migration and acquired during the acculturation process in Canada ${ }^{(1,4,5)}$.
A modifiable dietary risk factor associated with excessive weight is the consumption of food and drink products high in dietary sugars ${ }^{(6-8)}$. Such products include soft drinks, sweetened juices and other beverages, candies and chocolate, sugary baked goods, ice creams and other desserts. These products share several nutritional characteristics that make them unhealthy: they are energy dense (for solids), have a high content of free sugars and are often high in fats and saturated fats, while being low in fibre, protein, vitamins and minerals. Most of these products are also rich in high-fructose corn syrup which, when metabolized, may be linked to the development of chronic diseases $^{(9)}$. Furthermore, in Western countries, sweetened products are often sold in large portion sizes and are commonly consumed as snacks, both of which may contribute to energy imbalance ${ }^{(10)}$.

In the traditional cuisine of the Middle East region, sweetened tea is consumed on a daily basis. Other sweet 
products include a variety of pastries and desserts generally home-prepared and traditionally consumed during festivities or special occasions ${ }^{(11-14)}$. However, in the last few decades dietary patterns have changed considerably in the Middle East, with an increase in consumption of Western-type food including candies, soft drinks and junk foods. This has been accompanied by a rise in the prevalence of obesity and chronic diseases ${ }^{(11,15,16)}$. Similarly, Arab migrants are exposed to a new food environment when they come to Canada, where sweetened products are abundant, cheap, convenient, accessible and normatively consumed in the regular diet. Consumption patterns of sweetened products, however, are unknown in the Middle Eastern Canadian community.

To address the problems of overweight/obesity it is also important to understand how dietary patterns relate to energy expenditure. In Western countries, sweetened product consumption is associated with physical inactivity and sedentary behaviours, including television viewing and recreational computer use ${ }^{(17-19)}$. Such relationships are important to examine among Middle Eastern Canadians because they report one of the lowest levels of physical activity among all ethnic groups in Montreal $^{(20)}$ and in the country ${ }^{(21,22)}$.

Studying the consumption patterns of sweetened products is a difficult task because there is no international consensus on how to report and measure dietary sugars contained in foods and drinks ${ }^{(23)}$. The WHO suggests an upper intake limit of $10 \%$ of free sugars (percentage of total energy); which include all mono- and disaccharides added to foods by the manufacturer, cook or consumer, plus sugars naturally present in honey, syrups and fruit juices ${ }^{(6)}$. Health Canada recommends an upper intake limit of $25 \%$ of added sugars, but Canadian food composition tables contain data only on total sugars, which includes all mono- and disaccharides present in food and drinks ${ }^{(24)}$. Such tables do not allow the distinction between total sugars according to food sources and food processing.

There is evidence that food processing matters for obesity; processed sources of dietary sugars are positively associated with weight gain (e.g. soft drinks, sweets and cookies), whereas unprocessed sources of dietary sugars (e.g. fruits) are inversely associated with it ${ }^{(25)}$. To address the issue of food processing, researchers from the School of Public Health at the University of São Paulo introduced a new classification of foodstuffs based on the nature, extent and purpose of their processing ${ }^{(26)}$. This classification divides all foods and drinks into three groups: (i) foods that are unprocessed or minimally processed; (ii) processed culinary ingredients; and (iii) food and drink products that are processed or ultra-processed. The third group is hypothesized to be the most significant in the context of obesity and chronic diseases ${ }^{(27-30)}$.

In the current paper, we operationalize a definition of sweetened products adapted from the classification system developed in Brazil and apply it to: (i) describe the consumption patterns of sweetened products in a Catholic Middle Eastern Canadian community; and (ii) examine the associations between sweetened product consumption and physical activity, sedentary behaviours and BMI. These objectives are essential to address because the burden of overweight/obesity among Middle Eastern Canadians is an increasing public health issue; this is one of the growing migrant groups in Canada, constituting $>4 \%$ of the urban population of Montreal and Ottawa ${ }^{(2)}$.

\section{Methods}

\section{Design}

A two-stage cross-sectional study was conducted. During Stage $1,24 \mathrm{~h}$ recalls ( $n$ 42) were administered to measure total sugar intake (from all food sources), total energy intake, and to identify the list of sweetened products consumed in the studied community. This list served as the basis of an FFQ administered in Stage 2 to measure the daily consumption of sweetened products and to collect sociodemographic and behavioural data ( $n$ 192).

\section{Participants}

The Middle East Canadian community is a heterogeneous group composed mainly of Lebanese (41\%), Egyptian (12\%), Syrian (6\%), Moroccan (6\%) and Iraqi (6\%). The community is equally divided between Muslims and Christians $^{(2)}$. Religious affiliation is important to acknowledge in the Arab community since Muslims may follow dietary restrictions or prohibitions ${ }^{(31,32)}$.

The target population of the present study is an established Catholic Middle Eastern community living in Montreal, Canada. This population consists of first- and secondgeneration migrants primarily from Egypt, Lebanon and Syria. Recruitment and data collection were done at three Catholic Middle Eastern churches located in Montreal. Participation was solicited through public announcements and was limited to one respondent per household to avoid bias related to family customs. Participants were all volunteers and could withdraw from the study at any point.

Forty-two self-declared normoglycaemic individuals (twenty-five women, seventeen men) evenly distributed across age groups (18-30 years, 31-45 years and 46-60 years) participated in Stage 1. One hundred and ninetytwo individuals (105 women, eighty-seven men) participated in Stage 2, of whom two were not included in the analysis because of missing data/no answer. No individuals from Stage 1 participated in Stage 2. Self-reported normoglycaemic status was verified with a glycated $\mathrm{Hb}$ (HbA1c) test using a Cholestech GDX instrument (Cholestech Corporation, Hayward, CA, USA) ${ }^{(33)}$; an exclusion cut-off of $>6.5 \%$ was applied ${ }^{(34)}$.

The research protocol was submitted and approved by the ethics committee of the Centre Hospitalier de 
l'Université de Montréal (SL 06-063). All participants provided informed written consent.

\section{Definition of sweetened products}

We operationalized a definition of sweetened products that included all processed sources of total sugars using the classification of foodstuffs developed in Brazil ${ }^{(26)}$. Processed sources of total sugars are found in processed culinary ingredients extracted from unprocessed or minimally processed foods (such as sugars extracted from beets or canes). Sources of total sugars in this group are table sugar, honey and other natural sweeteners used by individuals to enhance the palatability of beverages, such as tea and coffee, or dishes. Processed sources of total sugars are also found in ultra-processed products defined as readyto-consume industry formulations manufactured mostly or entirely from industrial ingredients and containing little or no whole foods. Sources of total sugars in this group include candies, chocolate, sugary baked good, soft drinks, fruit juices and drinks, sweetened dairy products, as well as sweet sauces.

In the present paper, sweetened products are defined as all culinary processed ingredients and ultra-processed products for which total sugars exceeded $20 \%$ of total energy. The $20 \%$ cut-off mark was derived from the analysis of $24 \mathrm{~h}$ recalls in Stage 1 ( $n$ 42) and using the Canada Nutrient File (CNF) ${ }^{(35)}$. Our definition excludes unprocessed or minimally processed sources of total sugars found in fruits, legumes, vegetables, grains and milk. Therefore, it aligns with previous research ${ }^{(26)}$ and recommendations on dietary sugars ${ }^{(6-8)}$.

\section{Data collection}

The $24 \mathrm{~h}$ recalls were conducted by the lead author while the survey instruments in Stage 2 were completed via selfreport under the supervision of the lead author. The FFQ included a list of sweetened products identified from the $24 \mathrm{~h}$ recall analysis. Respondents were asked to report the average number of days per week, in a typical week (i.e. excluding festivities), they ate each listed product. They also reported how many portions of the product they typically ate or drank. Examples of portion sizes were taken from the CNF and provided to participants ${ }^{(35)}$. Lastly, participants were asked to indicate the time of the day when each product was usually consumed (i.e. breakfast, morning, lunch, afternoon, dinner, evening).

Sociodemographic and behavioural characteristics were collected using a self-reported questionnaire adapted from the Canadian Community Health Survey ${ }^{(36)}$. Participants were free to answer 'I don't know/I don't want to answer' to each question. Participants self-reported height and weight. BMI was calculated as $\mathrm{kg} / \mathrm{m}^{2}$ and using standard criteria of classification ${ }^{(37)}$ was classified as normal weight $(\geq 18.5$ and $\left.<25 \cdot 0 \mathrm{~kg} / \mathrm{m}^{2}\right)$, overweight $\left(\geq 25 \cdot 0\right.$ and $<30.0 \mathrm{~kg} / \mathrm{m}^{2}$ ) or obese $\left(\geq 30 \cdot 0 \mathrm{~kg} / \mathrm{m}^{2}\right)$. Education level was measured as the highest diploma obtained and coded as college/high school or university. Student status was registered as being a student or not at the time of the study. Employment was registered as being employed or not at the time of the study. Physical activity was enquired by asking "How many times per week do you exercise enough to sweat?', with answer choices ranging from 0 to $\geq 4$ times/week. Television viewing was measured by asking 'In the last 3 months, how much time have you spent watching television or movies on a typical day?', with answers choices ranging from 0 to $\geq 3 \mathrm{~h} / \mathrm{d}$. A similar question and answers were used for recreational computer use.

\section{Data analysis}

In Stage 1,24h recall data analysis was conducted by a trained nutritionist using the CNF. In Stage 2, consumption of sweetened products was calculated using the FFQ data on frequency of consumption and portion sizes and the average amount of total sugars contained in a mean portion of each food product using the CNF. For each product, this amount corresponded to the average amount of total sugars contained in all types of the given item (i.e. both commercial and home-prepared types). The relative share of each product to the total consumption of all sweetened products was also calculated. In all tables and analysis of the present paper, consumption of sweetened products is reported as daily grams of total sugars $(\mathrm{g} / \mathrm{d})$.

Analyses using Pearson correlation were performed between sociodemographic factors, sedentary activities, physical activity and BMI. Univariate regression analyses (generalized linear regression model, gamma distribution and log-link function) were then carried out to examine the associations between consumption of sweetened products and physical activity, sedentary activities and BMI, adjusting for age. Last, all variables significantly associated with sweetened product consumption were entered in a multivariate regression model, while adjusting for age. In the models, age and BMI were entered as continuous variables, while others were entered as ordinal: physical activity ( $0,1,2,3$ or $\geq 4$ times/week), recreational computer use $(<1 \mathrm{~h} / \mathrm{d}, 1-2 \mathrm{~h} / \mathrm{d}$ and $\geq 3 \mathrm{~h} / \mathrm{d})$ and television viewing $(<1 \mathrm{~h} / \mathrm{d}, 1-2 \mathrm{~h} / \mathrm{d}$ and $\geq 3 \mathrm{~h} / \mathrm{d})$. Statistical validity of the regression analysis was assessed using Akaike's information criterion and Pearson square (using the SPSS statistical software package version 19). Additionally, we tested whether considering liquid and solid sources of sweetened products separately generated any significant differences. We also verified whether fat content (daily grams of total fats from sweetened products) was related to the dependent and exposure variables, and if it could be a potential confounder or covariate.

\section{Results}

As measured in Stage 1 ( $n$ 42), total sugar intake from all food sources (regardless of processing) was $108.8 \mathrm{~g} / \mathrm{d}$ or 
$20 \cdot 3 \%$ of daily energy (9477 kJ (2265 kcal)). It was slightly higher in women $(21.6 \%)$ than in men (18.3\%); however, consumption in grams was higher in men $(131.0 \mathrm{~g} / \mathrm{d})$ than in women $(93.7 \mathrm{~g} / \mathrm{d})$.

Table 1 presents the list of twenty-six sweetened products identified in the $24 \mathrm{~h}$ recalls at Stage 1 and included in the present study. Oriental pastries (also known as baklava) were the only product found to be culturally specific to the Middle East region. Cereals were not included in the list since the total sugar content of various cereals found in the $\mathrm{CNF}$ ranged from $4 \%$ to $52 \%$. Fruit juices and drinks were combined into a single category based on the similarity of their total sugar content.

Table 1 Characteristics of sweetened products consumed in the Catholic Middle Eastern community of Montreal ( $n$ 190)

\begin{tabular}{lcc}
\hline Sweetened product & $\begin{array}{c}\text { Contribution* } \\
(\%)\end{array}$ & $\begin{array}{c}\text { Total sugar content十 } \\
(\%)\end{array}$ \\
\hline Soft drinks & $15 \cdot 3$ & $84-100$ \\
Fruit juices/drinks & $12 \cdot 8$ & $75-98$ \\
Sweetened coffee & $11 \cdot 0$ & $36-87$ \\
Chocolate (bars and spread) & $10 \cdot 3$ & $57-99$ \\
Cakes & $8 \cdot 8$ & $24-46$ \\
Muffins & $7 \cdot 9$ & $25-30$ \\
Cookies & $6 \cdot 8$ & $16-33$ \\
Sweetened tea & $4 \cdot 0$ & $36-87$ \\
Buns & $4 \cdot 0$ & $20-45$ \\
Honey & $2 \cdot 8$ & 100 \\
Chocolate milks & $2 \cdot 1$ & $57-61$ \\
Ice creams & $2 \cdot 0$ & $17-61$ \\
Jams & $1 \cdot 8$ & $38-64$ \\
Doughnuts & $1 \cdot 8$ & $22-26$ \\
Sweet yoghurts & $1 \cdot 8$ & $57-69$ \\
Brownies & $1 \cdot 7$ & $26-28$ \\
Maple syrup & $1 \cdot 7$ & 81 \\
Candies & $1 \cdot 7$ & $42-75$ \\
Baklavas & $0 \cdot 9$ & $24-30$ \\
Sweet sauces & $0 \cdot 6$ & $57-86$ \\
Gums & $0 \cdot 2$ & 100 \\
\hline
\end{tabular}

${ }^{*}$ Contribution of each product to total sweet product consumption (as a percentage of total sugars). This contribution is a function of the frequency of consumption, average portion consumption and total sugar content in mean portions.

†Total sugar content refers to the percentage of energy attributed to total sugars in each product. Percentages were calculated using the Canada Nutrient File ${ }^{(35)}$ and included all varieties of a given product. For example, ice cream products contain between $17 \%$ and $61 \%$ of energy from total sugars.
Participants at Stage 2 ( $n$ 190) were aged between 18 and 60 years old with a mean age of 35 (SD 12.8) years. Most participants were born in Egypt (31.9\%), Lebanon (25.1\%), Syria $(14 \cdot 7 \%)$ and other Middle Eastern countries including Kuwait, Palestine and Saudi Arabia (5.3\%). These individuals and their families migrated to Canada between 1962 and $2007,86 \%$ of whom arrived before 2000 . Another $23 \%$ of participants were born in Canada; they were secondgeneration migrants from parents born in the Middle East. Among the participants, $48 \%$ were normal weight, 36\% were overweight and 16\% were obese.

As measured by the FFQ at Stage 2, average consumption of sweetened products was $75 \cdot 4$ (SD 50.9) $\mathrm{g} / \mathrm{d}(n$ 190) with a range from 2.9 to $316 \mathrm{~g} / \mathrm{d}$, and followed a gammatype distribution. The share of each sweetened product to total sweetened product consumption (as a percentage of total sugars) is shown in Table 1 . The main sources of sweetened products were juices and beverages (soft drinks, fruit juices/drinks and sweetened coffee), chocolates and sugary baked goods (cookies, cakes and muffins).

Table 2 presents the consumption share of selected sweetened products according to the period of the day, as measured by the FFQ at Stage 2. Most products were consumed between meals, including $70 \cdot 4 \%$ of chocolate bars, $61.6 \%$ of cookies, $55.0 \%$ of cakes and $70.9 \%$ of ice creams. These were eaten mainly in the afternoon and during the evening. Almost two-thirds of soft drinks and sweetened juices were consumed during meals, whereas sweetened coffee and tea were consumed equally during and between meals.

Table 3 shows the consumption of sweetened products according to the participants' sociodemographic characteristics at Stage 2. Most importantly, younger individuals ate significantly more sweetened products than older individuals $(P<0 \cdot 01)$ and this was true for both liquid $(P<0 \cdot 01)$ and solid sources of sweetened products $(P<0 \cdot 02)$. Men consumed more sweets $(83.9 \mathrm{~g} / \mathrm{d})$ than women $(69 \cdot 0 \mathrm{~g} / \mathrm{d})$, and this difference was significant only for liquid sources $(P<0 \cdot 01)$. Higher consumption of sweetened products was also found among students, individuals without a university degree and those who

Table 2 Consumption of main sweetened products according to period of the day in the Catholic Middle Eastern community of Montreal (n 190)

\begin{tabular}{|c|c|c|c|c|c|c|}
\hline Sweetened product & Breakfast & Morning & Lunch & Afternoon & Supper & Evening \\
\hline Soft drinks & $4 \cdot 4^{*}$ & $4 \cdot 5$ & $30 \cdot 7$ & $17 \cdot 5$ & $28 \cdot 0$ & $14 \cdot 9$ \\
\hline Fruit juices and drinks & $23 \cdot 1$ & $9 \cdot 4$ & $22 \cdot 5$ & $20 \cdot 6$ & $15 \cdot 6$ & $8 \cdot 8$ \\
\hline Coffee (with sugar) & $38 \cdot 0$ & $21 \cdot 4$ & $10 \cdot 9$ & $15 \cdot 1$ & $5 \cdot 2$ & $9 \cdot 4$ \\
\hline Chocolate bars & $4 \cdot 6$ & $10 \cdot 8$ & $13 \cdot 8$ & $37 \cdot 2$ & $11 \cdot 2$ & $22 \cdot 4$ \\
\hline Cakes & $20 \cdot 2$ & $9 \cdot 3$ & $9 \cdot 3$ & $21 \cdot 7$ & $15 \cdot 5$ & $24 \cdot 0$ \\
\hline Muffins & $44 \cdot 1$ & $16 \cdot 1$ & $17 \cdot 2$ & $11 \cdot 8$ & $5 \cdot 4$ & $5 \cdot 4$ \\
\hline Cookies & $18 \cdot 9$ & $10 \cdot 1$ & $7 \cdot 7$ & $22 \cdot 5$ & $11 \cdot 8$ & $29 \cdot 0$ \\
\hline Tea (with sugar) & $25 \cdot 8$ & $9 \cdot 2$ & $7 \cdot 6$ & $8 \cdot 3$ & $8 \cdot 3$ & $40 \cdot 8$ \\
\hline Ice creams & $4 \cdot 9$ & $1 \cdot 0$ & $4 \cdot 8$ & $16 \cdot 5$ & $19 \cdot 4$ & $53 \cdot 4$ \\
\hline
\end{tabular}

*Each line shows the temporal distribution of consumption of each product for all individuals ( $n$ 190). For example, $4 \cdot 4 \%$ of all soft drinks in this community were consumed at breakfast, whereas $30 \cdot 7 \%$ were consumed at lunch. 
Table 3 Consumption of sweetened products according to sociodemographic characteristics in the Catholic Middle Eastern community of Montreal ( $n$ 190)

\begin{tabular}{|c|c|c|c|c|}
\hline Characteristic & $n$ & Mean* & SD & $P$ valuet \\
\hline Sex & & & & 0.06 \\
\hline Female & 104 & $69 \cdot 0$ & $4 \cdot 4$ & \\
\hline Male & 86 & $83 \cdot 1$ & $6 \cdot 1$ & \\
\hline Age (years) & & & & 0.01 \\
\hline $18-30$ & 84 & $81 \cdot 1$ & $46 \cdot 5$ & \\
\hline $31-45$ & 65 & $77 \cdot 6$ & $51 \cdot 9$ & \\
\hline $45-60$ & 41 & $54 \cdot 8$ & $42 \cdot 3$ & \\
\hline Household income $(\$ C A N) \ddagger$ & & & & 0.08 \\
\hline$<28000$ & 17 & $83 \cdot 9$ & $52 \cdot 5$ & \\
\hline $28000-50000$ & 42 & $89 \cdot 6$ & $68 \cdot 7$ & \\
\hline $51000-74000$ & 42 & $63 \cdot 4$ & $43 \cdot 5$ & \\
\hline $75000-100000$ & 37 & $70 \cdot 5$ & $36 \cdot 6$ & \\
\hline$>100000$ & 35 & $68 \cdot 7$ & $30 \cdot 3$ & \\
\hline \multicolumn{5}{|l|}{ Education level } \\
\hline College or high school & 65 & $84 \cdot 0$ & $66 \cdot 4$ & 0.43 \\
\hline University & 125 & $70 \cdot 9$ & $40 \cdot 9$ & \\
\hline \multicolumn{5}{|l|}{ Student status } \\
\hline Yes & 64 & $88 \cdot 6$ & $62 \cdot 2$ & 0.43 \\
\hline No & 126 & $68 \cdot 7$ & $51 \cdot 0$ & \\
\hline Employment & & & & 0.32 \\
\hline Yes & 51 & $75 \cdot 9$ & $48 \cdot 2$ & \\
\hline No & 139 & $73 \cdot 8$ & $58 \cdot 3$ & \\
\hline Civil status & & & & $0 \cdot 31$ \\
\hline Married/engaged & 91 & $64 \cdot 6$ & $48 \cdot 3$ & \\
\hline Single & 86 & $85 \cdot 6$ & $51 \cdot 9$ & \\
\hline Divorced/separated/widow & 13 & $82 \cdot 7$ & $51 \cdot 2$ & \\
\hline Time since immigration & & & & $0 \cdot 41$ \\
\hline Born in Canada & 44 & $87 \cdot 1$ & $62 \cdot 7$ & \\
\hline$\leq 10$ years & 31 & $77 \cdot 5$ & $35 \cdot 0$ & \\
\hline$\geq 11$ years & 115 & $68 \cdot 9$ & $47 \cdot 6$ & \\
\hline
\end{tabular}

*Mean daily amount of total sugars $(\mathrm{g} / \mathrm{d})$ from all sweetened products. +Univariate analyses with the generalized linear model (gamma distribution, log-link function) between sweetened product consumption and each sociodemographic variable, controlling for age.

$\ddagger$ Only respondents who agreed to report family income were included $(n 173)$.

were single or divorced/separated/widowed. Additionally, individuals born in Canada ate more sweetened products than recent immigrants, and recent immigrants ( $\leq 10$ years) ate more of these products than long-term migrants ( $\geq 11$ years). However, relatively high correlations were found between age and all of these variables: time since immigration $(R=0.36 ; P<0 \cdot 01)$, civil status $(R=0.49 ; P<0 \cdot 01)$, student status $(R=0.58 ; P<0 \cdot 01)$ and education level $(R=0 \cdot 18 ; P<0 \cdot 01)$. After controlling for age, all relationships between sociodemographic variables and consumption of sweetened products lost their statistical significance. Sociodemographic variables were not significantly related to the consumption level of either liquid or solid sources of sweetened products.

A low correlation was found between television viewing and recreational computer use $(R=0.16 ; P<0.05)$. Sedentary behaviours were not correlated with BMI. Table 4 shows the consumption of sweetened products according to BMI, physical activity and sedentary behaviours. After controlling for age, consumption of sweetened products was significantly higher in participants who spent more time using their computer for recreational purposes $(P<0 \cdot 01)$ and this association was significant for both solid $(P<0 \cdot 01)$
Table 4 Consumption of sweetened products according to BMI, physical activity and sedentary activities in the Catholic Middle Eastern community of Montreal ( $n$ 190)

\begin{tabular}{|c|c|c|c|c|c|}
\hline Predictor & $n$ & $\%$ & Mean* & SD & $P$ valuet \\
\hline BMl & & & & & 0.89 \\
\hline Normal weight & 91 & 48 & $81 \cdot 3$ & $55 \cdot 8$ & \\
\hline Overweight & 69 & 36 & $69 \cdot 7$ & $48 \cdot 9$ & \\
\hline Obese & 30 & 16 & $70 \cdot 5$ & $38 \cdot 3$ & \\
\hline Physical activitył & & & & & 0.01 \\
\hline No activity & 58 & 31 & $84 \cdot 6$ & $58 \cdot 9$ & \\
\hline 1 time/week & 53 & 28 & $76 \cdot 4$ & $46 \cdot 0$ & \\
\hline 2 times/week & 31 & 16 & $66 \cdot 4$ & $34 \cdot 8$ & \\
\hline 3 times/week & 30 & 16 & $53 \cdot 2$ & $37 \cdot 2$ & \\
\hline$\geq 4$ times/week & 18 & 9 & $95 \cdot 2$ & $67 \cdot 4$ & \\
\hline Television viewing & & & & & 0.02 \\
\hline$<1 \mathrm{~h} / \mathrm{d}$ & 121 & 64 & $70 \cdot 5$ & $49 \cdot 3$ & \\
\hline $1-2 \mathrm{~h} / \mathrm{d}$ & 61 & 32 & $84 \cdot 1$ & $53 \cdot 6$ & \\
\hline$\geq 3 \mathrm{~h} / \mathrm{d}$ & 8 & 4 & $88 \cdot 7$ & $54 \cdot 9$ & \\
\hline Recreational computer use & & & & & 0.00 \\
\hline$<1 \mathrm{~h} / \mathrm{d}$ & 80 & 42 & $62 \cdot 3$ & $39 \cdot 7$ & \\
\hline $1-2 \mathrm{~h} / \mathrm{d}$ & 56 & 30 & $76 \cdot 3$ & $48 \cdot 9$ & \\
\hline$\geq 3 \mathrm{~h} / \mathrm{d}$ & 54 & 28 & $94 \cdot 8$ & $62 \cdot 2$ & \\
\hline
\end{tabular}

${ }^{*}$ Mean daily amount of total sugars $(\mathrm{g} / \mathrm{d})$ from all sweetened products. tAll univariate regressions were controlled for age and performed with the generalized linear model (scale response was gamma with log-link function). ¥A quadratic regression analysis was performed to account for the U-shaped relationship between physical activity and consumption of sweetened products.

and liquid sources $(P<0 \cdot 01)$ of sweetened products. Consumption of sweetened products was also significantly higher in participants who spent more time watching television $(P<0 \cdot 01)$ after controlling for age, but this association was not significant when solid and liquid sources of sweetened products were considered separately.

An inverse but non-significant relationship was found between sweetened product consumption and BMI $(P<0 \cdot 89)$, and this was true for both liquid and solid sources. Furthermore, a U-shaped relationship was found between level of physical activity and consumption of sweetened products $(P<0 \cdot 01)$; there was a gradual and inverse linear relationship between consumption of these products and the level of physical activity from individuals who did not do any exercise to those who exercised up to 3 times/week. However, the highest consumers of sweetened products were found among participants who exercised the most ( $\geq 4$ times/week). In a post hoc test, the addition of a quadratic term to the model for physical activity was statistically significant $(P<0 \cdot 04)$. The nature of the association between level of physical activity and consumption of sweetened products was the same for both liquid and solid sources.

Finally, in the multivariate generalized linear regression model $(\chi=29.9 ; P<0.001)$, both age $(\exp (\beta)=0.99$; $P<0 \cdot 01)$ and level of physical activity $(\exp (\beta)=1 \cdot 08$; $P<0 \cdot 01)$ were independently and inversely associated with consumption of sweetened products. The positive value of the exponentiated betas for physical activity indicates that consumption of sweetened products rose after a certain level of physical activity $(\geq 4 \mathrm{~h} /$ week). Recreational computer use $(\exp (\beta)=1 \cdot 17 ; P<0 \cdot 01)$ was 
positively associated with consumption of these products. No differences were observed when multivariate analyses were ran for solid and liquid sources separately.

Fat consumption ( $\mathrm{g}$ total fat/d) was moderately related to sweetened product consumption $(R=0.50 ; P<0 \cdot 01)$. It was not related to $\operatorname{sex}(R=0.54 ; P<0 \cdot 161)$ nor to physical activity $(R=0.17 ; P<0.811)$, and had a low correlation with age $(R=0 \cdot 26 ; P<0 \cdot 01)$ and recreational computer use $(R=0 \cdot 21 ; P<0 \cdot 01)$. Adding fat consumption as a covariate in the multivariate model did not alter the direction nor change the significance level of the measured associations.

\section{Discussion}

The present paper describes for the first time the consumption patterns of sweetened food and drink products in a Catholic Middle Eastern Canadian community and reports its associations with sedentary behaviours, physical activity and BMI.

The consumption level of sweetened products amounted to $75 \cdot 4 \mathrm{~g}$ total sugars/d or $15 \cdot 1 \%$ of daily energy intake (based on $8368 \mathrm{~kJ}(2000 \mathrm{kcal}) / \mathrm{d})$, which far exceeds the WHO upper limit for free sugars ${ }^{(6)}$ set at $10 \%$. This is true for all participants, regardless of their BMI. The consumption level of sugar in the Catholic Middle Eastern Canadian community is also higher than the one reported for Lebanese living in Beirut $(11.4 \%$ of daily energy intake $^{(15)}$. Elsewhere, higher levels of sugar intake ( $>20 \%$ of daily energy intake) were reported in rural Egypt, mostly due to the consumption of sweetened tea ${ }^{(38)}$, as well as in children of aged 6-12 years who consumed sugary baked goods in Syria ${ }^{(39)}$.

In the traditional diets of the Middle East region sweetened tea was consumed daily and home-prepared pastries and desserts were prepared and consumed on festivities ${ }^{(12-14)}$. However, most of the processed sources of dietary sugars identified in our study are ultraprocessed products and include soft drinks, fruit juices and drinks, chocolates and sugary baked goods, as well as sweetened coffee. These products are typical of the Western-type diet ${ }^{(40)}$ and designed to be consumed as snacks ${ }^{(29)}$. This is consistent with our finding that most sweetened products were consumed between meals.

Sweetened product consumption from both liquid and solid sources was significantly higher among younger individuals. Similar relationships were reported for total sugars consumption in Canada ${ }^{(41)}$ and for free sugars consumption in Lebanon ${ }^{(15)}$. We also found that consuming sweetened products was associated with television viewing and recreational computer use. In Western countries, similar relationships were reported between these behaviours and consumption of soft drinks and sugary foods ${ }^{(17-19,42)}$

The relationship between consumption of sweetened products and level of physical activity was less straightforward. Inactive individuals consumed more sweetened food and drink products than low and moderately active individuals. One study reported a similar association with soft drink consumption ${ }^{(19)}$. However, we also noted that very physically active individuals ( $\geq 4$ times/week) reported the highest consumption level of sweetened products. In a previous paper we reported that sweetened products are consumed by Middle Eastern Canadians while performing both physical and mental activities ${ }^{(43)}$. Marketing and sales efforts of sweetened products are indeed focused on promoting their energizing properties and association with sports ${ }^{(44)}$.

We observed an inverse (but not significant) relationship between consumption of sweetened products and BMI. Similar results are reported in other cross-sectional studies $^{(42,45)}$. Our result must be interpreted by taking into account the cross-sectional design and the fact that consumption of sweets is related to health concerns and weight-loss intention $^{(46)}$. Indeed, at the time of the study, individuals with excessive weight reported a higher preoccupation with watching/restricting their dietary intake than normal weight individuals (data not shown). It is also possible that overweight and obese participants underreported their weight or under-reported their consumption of sweetened products. Because of the above limitations our data cannot be taken as evidence that consumption of sweetened products does not affect weight gain. Indeed, such a relationship is well attested in longitudinal and clinical studies in the literature $\mathrm{e}^{(25,47-51)}$.

Finally, in the multivariate analysis, we found that recreational computer use, physical activity and age were independently associated to the consumption of sweetened products. This means that, at least in this community, computer use is a better marker for sedentary behaviour than television viewing. This may reflect a shift in the use of technology, especially by adolescents and young adults, where computers, along with new media tools such as YouTube and Facebook, are replacing television as the number one sedentary activity. Excessive recreational computer use $(>3 \mathrm{~h} / \mathrm{d})$ was associated with the consumption of sugary drinks, independent of television viewing, in a sample of Californian adolescents ${ }^{(52)}$.

Other limitations of our study included the fact that participants were self-selected into the study. Nonrespondents would include individuals not attending church/not participating in church activities. However, the vast majority of Arab Canadians (94\%) describe themselves as being part of a religious faith ${ }^{(2)}$ and there is no reason to believe that characteristics of church attenders and nonattenders differ in terms of the variables examined herein. Our sample, however, is restricted to individuals with a medium to high socio-economic profile.

\section{Implications and conclusion}

The findings of the present study have important implications for the prevention and management of overweight and 
obesity in the Middle Eastern Canadian population. The consumption level of sweetened products largely exceeds the recommended upper intake of free sugars as set by the $\mathrm{WHO}^{(6)}$ and this is true for normal weight, overweight and obese individuals. To reduce intake of sugars, consumption of soft drinks, juices and beverages, chocolates and sugary baked goods should be targeted, primarily when eaten as snacks between meals. Health promotion initiatives should also focus on sedentary behaviours and physical activity, both of which are associated with consumption of these products. The association between physical activity and consumption of sweetened products requires further examination especially in very active individuals who may overuse sweetened products as the main source of energy while exercising. This is important considering that Middle East Canadians report one of the lowest levels of physical activity in the country ${ }^{(21,22)}$

The study also has implications for migrant health studies. Most sweetened products consumed by our sampled community are ultra-processed products which are characterized by a poor dietary quality ${ }^{(27,28)}$ and associated with weight gain and the development of chronic diseases ${ }^{53,54)}$. These products consumed as snacks are increasingly replacing foods and ingredients use to prepare meals and dishes ${ }^{(29,30)}$. This is important for migrants exposed to a new food environment when they come to Canada or the USA where sweetened products are cheap, abundant, attractive, convenient, and part of the food culture. Using the methodology described in the present paper, future studies could focus on describing the consumption patterns of sweetened foods and beverages in other migrant communities to address their role in increasing the burden of overweight/obesity and chronic diseases.

\section{Acknowledgements}

Sources of funding: This research received no specific grant from any funding agency in the public, commercial or not-for-profit sectors. Conflicts of interest: The authors report no conflict of interests. Authors' contributions: The empirical study was planned by all authors, and was supervised by M.D. Data preparation and analysis was undertaken by J.-C.M. The initial draft of the paper was prepared by J.-C.M., following extensive discussions with O.R., M.C. and M.D. Successive drafts were developed by J.-C.M., with inputs from the other co-authors. All authors have reviewed and approved the final version. Acknowledgements: The authors wish to thank Carlos Augusto Monteiro for his comments on the definition of sweet food and drink products.

\section{References}

1. Tremblay MS, Perez CE, Ardern CI et al. (2005) Obesity, overweight and ethnicity. Health Rep 16, 23-34.
2. Health Canada (2007) The Arab community. http:// www.statcan.gc.ca/pub/89-621-x/89-621-x2007009-eng.htm (accessed June 2012).

3. Liu R, So L, Mohan S et al. (2010) Cardiovascular risk factors in ethnic populations within Canada: results from national cross-sectional surveys. Open Med 4, e143-e153.

4. Nakanishi S, Okubo M, Yoneda M et al. (2004) A comparison between Japanese-Americans living in Hawaii and Los Angeles and native Japanese: the impact of lifestyle westernization on diabetes mellitus. Biomed Pharmacother $\mathbf{5 8}, 571-577$.

5. McDonald JT \& Kennedy S (2005) Is migration to Canada associated with unhealthy weight gain? Overweight and obesity among Canada's immigrants. Soc Sci Med 61, 2469-2481.

6. World Health Organization (2003) Diet, Nutrition and the Prevention of Chronic Diseases. Report of the Joint WHO/ FAO Expert Consultation. WHO Technical Report Series no. 916. Geneva: WHO.

7. Lustig RH, Schmidt LA \& Brindis CD (2012) Public health: the toxic truth about sugar. Nature 482, 27-29.

8. Johnson RK, Appel LJ, Brands M et al. (2009) Dietary sugars intake and cardiovascular health: a scientific statement from the American Heart Association. Circulation 120, 1011-1020.

9. Lustig RH (2010) Fructose: metabolic, hedonic, and societal parallels with ethanol. J Am Diet Assoc 110, 1307-1321.

10. Chapelot D (2011) The role of snacking in energy balance: a biobehavioral approach. J Nutr 141, 158-162.

11. Hassan-Wassef H (2004) Food habits of the Egyptians: newly emerging trends. East Mediterr Health J 10, 898-915.

12. Issa C, Salameh P, Batal M et al. (2009) The nutrient profile of traditional Lebanese composite dishes: comparison with composite dishes consumed in France. Int J Food Sci Nutr 60, Suppl. 4, 285-295.

13. Galal OM (2002) The nutrition transition in Egypt: obesity, undernutrition and the food consumption context. Public Health Nutr 5, 141-148.

14. Nickles HG (1975) La cuisine au Moyen-Orient. Amsterdam: Time-Life.

15. Nasreddine L, Hwalla N, Sibai A et al. (2006) Food consumption patterns in an adult urban population in Beirut, Lebanon. Public Health Nutr 9, 194-203.

16. Musaiger AO \& Al-Hazzaa HM (2012) Prevalence and risk factors associated with nutrition-related noncommunicable diseases in the Eastern Mediterranean region. Int J Gen Med 5, 199-217.

17. Must A \& Tybor DJ (2005) Physical activity and sedentary behavior: a review of longitudinal studies of weight and adiposity in youth. Int J Obes (Lond) 29, Suppl. 2, S84-S96.

18. Hetherington MM, Anderson AS, Norton GN et al. (2006) Situational effects on meal intake: a comparison of eating alone and eating with others. Physiol Behav 88, 498-505.

19. Rehm CD, Matte TD, Van Wye G et al. (2008) Demographic and behavioral factors associated with daily sugar-sweetened soda consumption in New York City adults. J Urban Health 85, 375-385.

20. O'Loughlin J, Maximova K, Tan Y et al. (2007) Lifestyle risk factors for chronic disease across family origin among adults in multiethnic, low-income, urban neighborhoods. Ethn Dis 17, 657-663.

21. Tremblay MS, Bryan SN, Perez CE et al. (2006) Physical activity and ethnicity: evidence from the Canadian Community Health Survey. Can J Public Health 97, 271-276.

22. Dogra S, Meisner BA \& Ardern CI (2010) Variation in mode of physical activity by ethnicity and time since immigration: a cross-sectional analysis. Int J Behav Nutr Phys Act 7, 75.

23. Cummings JH \& Stephen AM (2007) Carbohydrate terminology and classification. Eur J Clin Nutr 61, Suppl. 1, S5-S18. 
24. Health Canada (2012) Dietary references intakes. http:// www.hc-sc.gc.ca/fn-an/alt_formats/hpfb-dgpsa/pdf/nutrition/ dri_tables-eng.pdf (accessed April 2012).

25. Mozaffarian D, Hao T, Rimm EB et al. (2011) Changes in diet and lifestyle and long-term weight gain in women and men. N Engl J Med 364, 2392-2404.

26. Monteiro CA, Levy RB, Claro RM et al. (2010) A new classification of foods based on the extent and purpose of their processing. Cad Saude Publica 26, 2039-2049.

27. Monteiro CA, Levy RB, Claro RM et al. (2011) Increasing consumption of ultra-processed foods and likely impact on human health: evidence from Brazil. Public Health Nutr 14, 5-13.

28. Moubarac J-C, Martins AP, Claro RM et al. (2012) Consumption of ultra-processed foods and likely impact on human health. Evidence from Canada. Public Health Nutr (Epublication ahead of print version).

29. Monteiro CA, Gomes FS \& Cannon G (2010) The snack attack. Am J Public Health 100, 975-981.

30. Monteiro CA \& Cannon G (2012) The impact of transnational 'big food' companies on the South: a view from Brazil. PLoS Med 9, e1001252.

31. Sabate J (2004) Religion, diet and research. Br J Nutr 92 , 199-201.

32. Vallianatos H \& Raine K (2008) Consuming food and constructing identities among Arabic and South Asian immigrant women. Food Culture Soc 11, 355-360.

33. Cholestech Corporation (2004) Technical focus: Cholestech GDX System. Hayward, CA: Cholestech Corporation.

34. American Diabetes Association (2011) Diagnosis and classification of diabetes mellitus. Diabetes Care 34, Suppl. 1, S62-S69.

35. Health Canada (2012) Canada nutrient file. http://webprod3. hc-sc.gc.ca/cnf-fce/index-eng.jsp (accessed March 2012).

36. Health Canada (2003) Enquête sur la santé dans les collectivités canadiennes (ESCC). Questionnaire pour Cycle 2.1. http://www.statcan.gc.ca/concepts/health-sante/cycle2_1/ pdf/cchs-escc-fra.pdf (accessed June 2012).

37. Pi-Sunyer FX (2000) Obesity: criteria and classification. Proc Nutr Soc 59, 505-509.

38. Hassan H, Moussa W \& Ismail I (2006) Assessment of Dietary Changes and their Health Implications in Countries Facing the Double Burden of Malnutrition: Egypt, 1980 to 2005. The Double Burden of Malnutrition, Case Studies from Six Developing Countries. FAO Food and Nutrition Paper no. 84. Rome: FAO.

39. Jaghasi I, Hatahet W \& Dashash M (2012) Dietary patterns and oral health in schoolchildren from Damascus, Syrian Arab Republic. East Mediterr Health J 18, 358-364.

40. Guthrie JF \& Morton JF (2000) Food sources of added sweeteners in the diets of Americans. J Am Diet Assoc 100, $43-51$.
41. Blanchet C, Plante C \& Rochette L (2009) La consommation alimentaire et les apports nutritionnels des adultes québécois. http://www.inspq.qc.ca/pdf/publications/931_ RapportNutritionAdulte.pdf (accessed June 2012).

42. Andersen LF, Lillegaard IT, Overby N et al. (2005) Overweight and obesity among Norwegian schoolchildren: changes from 1993 to 2000. Scand J Public Health 33, 99-106.

43. Moubarac J-C, Cargo M, Receveur O et al. (2012) Describing the situational contexts of sweetened product consumption in a Middle Eastern Canadian Community: application of a Mixed Method Design. PLoS One 7, e44738.

44. Deldicque L \& Francaux M (2008) Functional food for exercise performance: fact or foe? Curr Opin Clin Nutr Metab Care 11, 774-781.

45. Bandini LG, Vu D, Must A et al. (1999) Comparison of high-calorie, low-nutrient-dense food consumption among obese and non-obese adolescents. Obes Res 7, 438-443.

46. Mullie P, Aerenhouts D \& Clarys P (2012) Demographic, socioeconomic and nutritional determinants of daily versus non-daily sugar-sweetened and artificially sweetened beverage consumption. Eur J Clin Nutr 66, 150-155.

47. Bray GA (2010) Soft drink consumption and obesity: it is all about fructose. Curr Opin Lipidol 21, 51-57.

48. Hu FB \& Malik VS (2010) Sugar-sweetened beverages and risk of obesity and type 2 diabetes: epidemiologic evidence. Physiol Behav 100, 47-54.

49. Malik VS, Schulze MB \& Hu FB (2006) Intake of sugarsweetened beverages and weight gain: a systematic review. Am J Clin Nutr 84, 274-288.

50. Vartanian LR, Schwartz MB \& Brownell KD (2007) Effects of soft drink consumption on nutrition and health: a systematic review and meta-analysis. Am J Public Health 97, 667-675.

51. Schulze MB, Manson JE, Ludwig DS et al. (2004) Sugar-sweetened beverages, weight gain, and incidence of type 2 diabetes in young and middle-aged women. JAMA 292, 927-934.

52. Shi L \& Mao Y (2010) Excessive recreational computer use and food consumption behaviour among adolescents. Ital J Pediatr 36, 52.

53. Asfaw A (2011) Does consumption of processed foods explain disparities in the body weight of individuals? The case of Guatemala. Health Econ 20, 184-195.

54. Tavares LF, Fonseca SC, Garcia Rosa ML et al. (2011) Relationship between ultra-processed foods and metabolic syndrome in adolescents from a Brazilian Family Doctor Program. Public Health Nutr (Epublication ahead of print version). 